\title{
One-Pot Synthesis of Co-Based Coordination Polymer Nanowire for Li-Ion Batteries with Great Capacity and Stable Cycling Stability
}

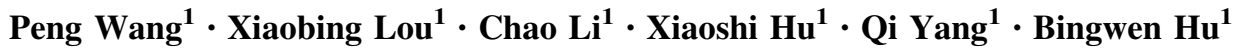

Received: 29 September 2017/ Accepted: 14 November 2017/Published online: 8 December 2017

(C) The Author(s) 2017. This article is an open access publication

\section{Highlights}

- Amide-group-coordinated cobalt-terephthalonitrile (Co-BDCN) coordination polymers, with a diameter distribution of 45-55 nm, were synthesized by a one-pot solvothermal method.

- Reversible capacity of $1132 \mathrm{mAh} \mathrm{g}^{-1}$ was achieved at a current density of $100 \mathrm{~mA} \mathrm{~g}^{-1}$.

\begin{abstract}
Nanowire coordination polymer cobalt-terephthalonitrile (Co-BDCN) was successfully synthesized using a simple solvothermal method and applied as anode material for lithium-ion batteries (LIBs). A reversible capacity of $1132 \mathrm{mAh} \mathrm{g}^{-1}$ was retained after 100 cycles at a rate of $100 \mathrm{~mA} \mathrm{~g}^{-1}$, which should be one of the best LIBs performances among metal organic frameworks and coordination polymers-based anode materials at such a rate. On the basis of the comprehensive structural and morphology characterizations including fourier transform infrared spectroscopy, ${ }^{1} \mathrm{H}$ NMR, ${ }^{13} \mathrm{C}$ NMR, and scanning electron microscopy, we demonstrated that the great electrochemical performance of the as-synthesized Co-BDCN coordination polymer can be attributed to the synergistic effect of metal centers and organic ligands, as well as the stability of the nanowire morphology during cycling.
\end{abstract}

Electronic supplementary material The online version of this article (https://doi.org/10.1007/s40820-017-0177-x) contains supplementary material, which is available to authorized users.

Qi Yang

qyang@lps.ecnu.edu.cn

1 State Key Laboratory of Precision Spectroscopy, Shanghai Key Laboratory of Magnetic Resonance, School of Physics and Materials Science, East China Normal University, Shanghai 200062, People's Republic of China

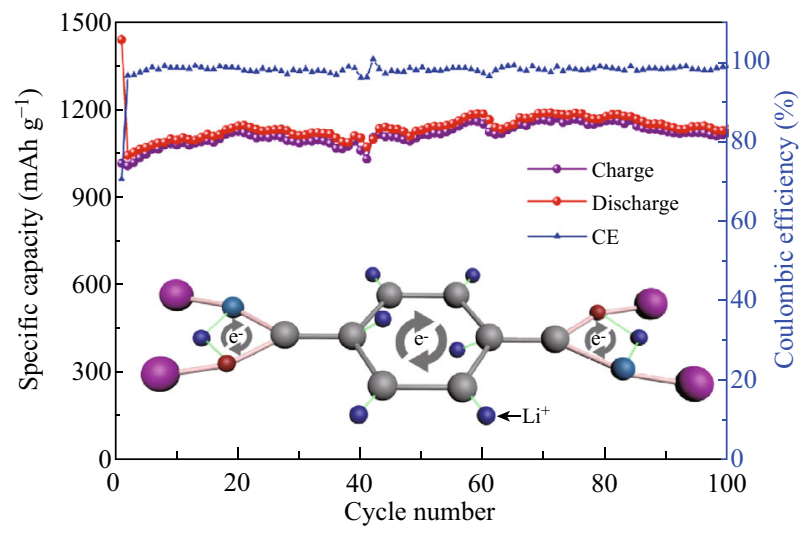

Keywords Nanowire - Coordination polymer · Lithiumion battery · Anode · Ultra-high capacity

\section{Introduction}

Rechargeable lithium-ion batteries (LIBs) have been finding increasing number of applications in a variety of fields, including portable electronic devices, electrical energy storage (EES), electric vehicles (EVs), and hybrid electric 
vehicles (HEVs) [1]. Given the commercial anode graphite possesses a low theoretical capacity of $372 \mathrm{mAh} \mathrm{g}^{-1}$, developing high-capacity anode materials is vital for aforementioned applications, particularly in areas where application of miniaturization is increasing. To develop futuristic high-performance anode materials, stable structure with abundant lithiation sites is necessary. To this end, metallic oxide-based [2-10], Sn-based [11, 12], Si-based $[13,14]$, and P-based [15-18] anode materials have been widely studied. Although their theoretical capacity is high, their cycling stability is poor due to large volume changes during the charge-discharge process [19-22].

Metal organic frameworks (MOFs) or coordination polymers (CPs), which are assembled by inorganic metal ions as vertices and organic ligands as linkers, have attracted tremendous attention in recent years [23-25]. By varying the metal centers and functional linkers, MOFs with various pore sizes and structures can be designed to cater for the increasing demands in the fields of catalysis, sensing, gas storage, drug delivery, and proton conductivity $[26,27]$. Recently, the electrochemical applications, especially for LIBs, have attracted significant attention due to their tremendous potential as both cathode [28-30] and anode materials [31-35]. MOF-177 [36], $\mathrm{Zn}_{3}(\mathrm{HCOO})_{6}$ [37], Mn-LCP [38], Mn-BTC [39], $\mathrm{Co}_{2}(\mathrm{OH})_{2} \mathrm{BDC}$ [40], BiCPs [41], and CoBTC [42] have been applied as anode (Table S1). For example, $\mathrm{Co}_{2}(\mathrm{OH})_{2} \mathrm{BDC}$ exhibited reversible capacity of $650 \mathrm{mAh} \mathrm{g}^{-1}$ after 100 cycles at current density of $50 \mathrm{~mA} \mathrm{~g}^{-1}$ [40]. In these CPs or MOFs, carboxylate groups (e.g., 1,3,5-benzenetricarboxylate and 1,4benzenedicarboxylate) are usually used to coordinate with different metal centers (e.g., Mn, Co, and Zn). During the charging process, $\mathrm{Li}^{+}$ions are inserted mainly to the organic moiety (including the carboxylate group and the benzene ring) in these MOFs [39, 42]. The electron-donating effect of the carboxylate group and the benzene ring is considered the main impetus in storing lithium ions. Conjugated dicarboxylates can eventually serve as anode materials without any metal center [43]. However, CP- or MOF-based electrodes with other kinds of organic linkers are seldom used.

Herein, we selected terephthalonitrile as the organic linker and $\mathrm{Co}\left(\mathrm{NO}_{3}\right)_{2} \cdot 6 \mathrm{H}_{2} \mathrm{O}$ as the metal source, and synthesized an amide-group-coordinated $\mathrm{CP}$ with nanowirelike structure using a simple solvothermal method. The coordination participation of the amide group showed a higher $\mathrm{Li}^{+}$storage performance as compared to $\mathrm{Co}_{2}(-$ $\mathrm{OH})_{2} \mathrm{BDC}$, which uses the carboxylate group as a linker. A reversible capacity of $1132 \mathrm{~mA} \mathrm{~g}^{-1}$ was retained after 100 cycles at a rate of $100 \mathrm{~mA} \mathrm{~g}^{-1}$. The synergistic effect between the organic linker and the $\mathrm{Co}^{2+}$ center, as well as the excellent stability of the nanowire-like structure, may account for the superior electrochemical performance.

\section{Experimental}

\subsection{Materials Synthesis}

Co-BDCN was solvothermally synthesized with $\mathrm{Co}\left(\mathrm{NO}_{3}\right)_{2} \cdot 6 \mathrm{H}_{2} \mathrm{O}$ (5 mmol, Aladdin, $\left.99.99 \%\right)$ and terephthalonitrile (5 mmol, Aladdin, 99\%) in N,N-dimethylformamide (DMF, $50 \mathrm{~mL}$, Sinopharm, AR) solution. The reactants were stirred for $10 \mathrm{~min}$ at room temperature to achieve complete dissolution and then transferred to a $100 \mathrm{~mL}$ Teflon-lined stainless steel autoclave before heating at $150{ }^{\circ} \mathrm{C}$ for 3 or $24 \mathrm{~h}$. The samples obtained after 3 and $24 \mathrm{~h}$ will be referred to as Co-BDCN-3h and CoBDCN-24h, respectively. After cooling to room temperature, the product was filtered and successively washed by DMF and ethanol for three times to remove surplus reactants. The product was finally obtained by drying at $70{ }^{\circ} \mathrm{C}$ for $12 \mathrm{~h}$. It is noteworthy that the direct synthesis of CoBDCN-24h from terephthalamide and $\mathrm{Co}\left(\mathrm{NO}_{3}\right)_{2} \cdot 6 \mathrm{H}_{2} \mathrm{O}$ failed due to the very low solubility of terephthalamide in the available solvents (DMF, methanol, alcohol, and water).

\subsection{Materials Characterizations}

A Rigaku Ultima IV X-ray diffractometer (XRD) with Cu$\mathrm{K} \alpha$ radiation $(V=35 \mathrm{kV}, I=25 \mathrm{~mA}, \lambda=1.5418 \AA)$ was used to analyze the crystal phase of the as-prepared materials. $\mathrm{N}_{2}$-sorption isotherms and BET surface area were measured at $77 \mathrm{~K}$ with a 02108-KR-1 system (Quantachrome). The morphologies of the samples were characterized by scanning electron microscopy (SEM, Hitachi S-2400, Japan). Before initiating the test, the samples were mounted on aluminum stubs and sputtered with gold. Thermogravimetric analysis (TGA) was performed using a STA 449 F3 Jupiter ${ }^{\circledR}$, which simultaneously acted as a thermo-analyzer. Temperature was varied from room temperature to $800{ }^{\circ} \mathrm{C}$ at a heating rate of $10{ }^{\circ} \mathrm{C} \mathrm{min}{ }^{-1}$. A Nicolet-Nexus 670 infrared spectrometer was used to perform Fourier transform infrared spectroscopy (FTIR) analysis. The cells for ex situ SEM test were cycled 50 times and discharged to $0.01 \mathrm{~V}$ to reduce the reactivity of the electrode. After that, we disassembled the battery in a glove box filled of pure argon and washed the electrode several times with DMC to remove the residual electrolyte. The electrode was tailored and pasted in conductive carbon adhesive tape directly before the test. The inductively coupled plasma (ICP) test was performed on Thermo IRIS Intrepid II XSP spectrometer. Varian $700 \mathrm{M}$ was used to collect ${ }^{1} \mathrm{H}$ nuclear magnetic resonance $\left({ }^{1} \mathrm{H}-\mathrm{NMR}\right)$ spectra in liquid state. About 1-mg samples were dispersed in $0.5 \mathrm{~mL}$ DMSO-6d. Then the liquids were 
heated at $80{ }^{\circ} \mathrm{C}$ for $5 \mathrm{~min}$ and ultrasonically vibrated for 5 more minutes before the ${ }^{1} \mathrm{H}-\mathrm{NMR}$ test. Bruker $600 \mathrm{M}$ was used to collect ${ }^{1} \mathrm{H}-\mathrm{NMR}$ spectra in the solid state.

\subsection{Battery Performance Measurements}

All electrochemical measurements were taken at room temperature. The active material (weight ratio: $80 \%$ ), conducting additive (Super-P carbon black, weight ratio: $10 \%$ ), and the binder (carboxymethyl cellulose sodium or CMC, weight ratio: 10\%) were homogenously mixed in deionized water (solvent) for at least $3 \mathrm{~h}$ to produce a slurry. The thus-obtained slurry was coated onto $\mathrm{Cu}$ foil and dried at $70{ }^{\circ} \mathrm{C}$ in vacuum oven for $12 \mathrm{~h}$. The electrodes were punched into round plates (diameter of $14.0 \mathrm{~mm}$ ). The loading of the as-prepared electrodes is about $1.0 \mathrm{mg} \mathrm{cm}^{-2}$. $1 \mathrm{M} \mathrm{LiPF}_{6}$ in EC-DMC-EMC (1:1:1 in volume) was used as the electrolyte. Finally, a coin cell (CR2032) was assembled by the as-prepared anode, a Celgard 2325 separator (diameter of $19.0 \mathrm{~mm}$ ), a pure lithium wafer (counter electrode), and electrolyte in an argon-filled glove box, with oxygen and water contents less than $0.1 \mathrm{ppm}$. The galvanostatic charge and discharge and rate tests were performed on a LAND 2001A battery test system in the voltage range of $0.01-3.0 \mathrm{~V}$. Cyclic voltammetry (CV) and electrochemical impedance spectroscopy (EIS) were performed on an electrochemical workstation (CHI660e) at a scan rate of $0.2 \mathrm{mV} \mathrm{s}^{-1}$ in the voltage range of $0.01-3.0 \mathrm{~V}$.

\section{Results and Discussion}

FTIR is a convenient tool to study the binding patterns of organic linkers and $\mathrm{Co}^{2+}$. As shown in Fig. 1a, the sharp absorption band at $2233 \mathrm{~cm}^{-1}$ of terephthalonitrile corresponds to $v(\mathrm{C} \equiv \mathrm{N})$; however, no absorption of $\mathrm{C} \equiv \mathrm{N}$ can be observed in Co-BDCN-3h and Co-BDCN-24h, indicating the disappearance of $\mathrm{C} \equiv \mathrm{N}$ after reaction. For CoBDCN-3h, the new peaks at 1661, 1619, 1410, and $1386 \mathrm{~cm}^{-1}$ can be assigned to the $v(\mathrm{C}=\mathrm{O})$ stretching mode (or amide I), amide II, $v(\mathrm{C}-\mathrm{N})$, and amide III, respectively,
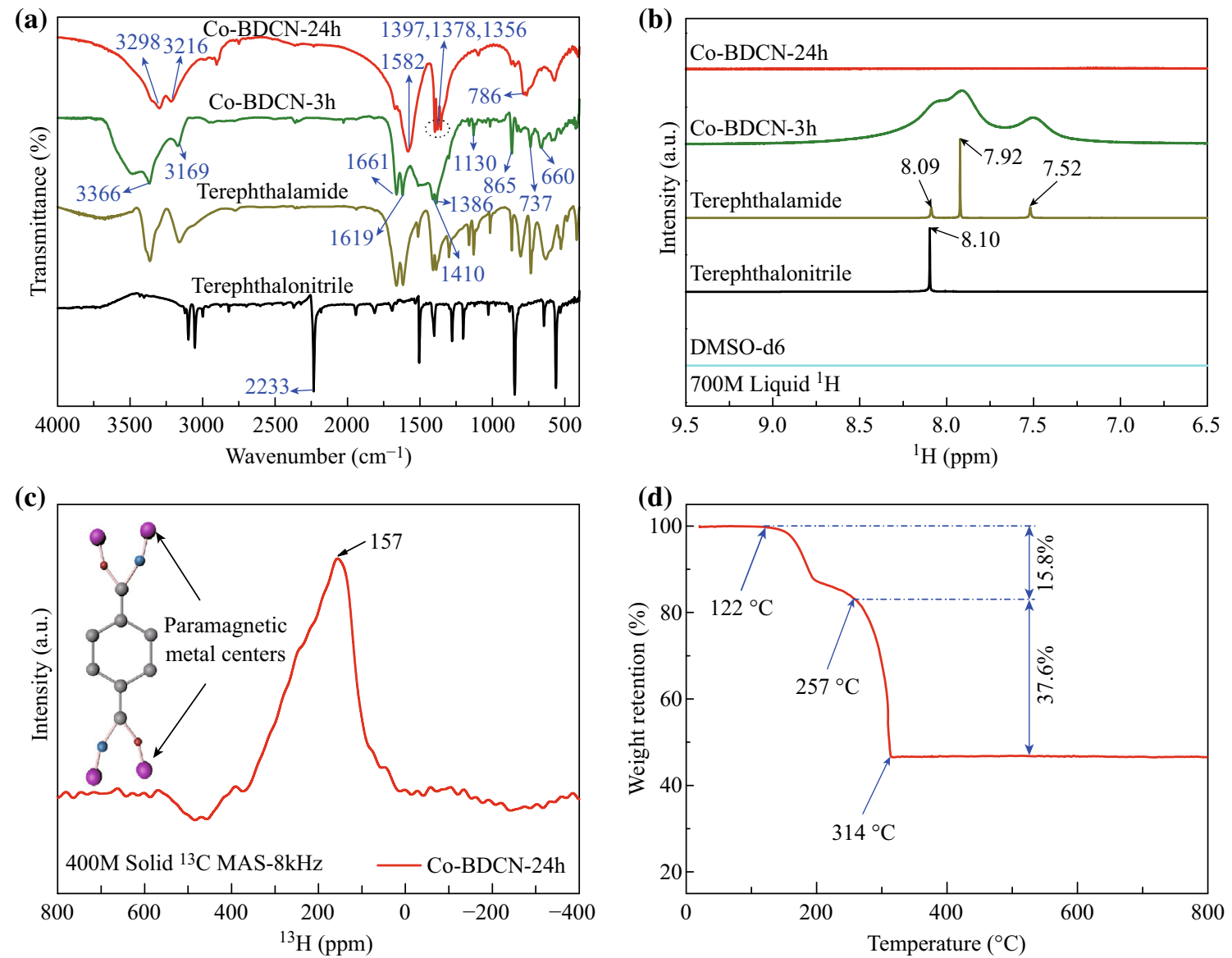

Fig. 1 a FTIR spectra of Co-BDCN-24h, Co-BDCN-3h, terephthalamide, and terephthalonitrile. b ${ }^{1} \mathrm{H}$ NMR spectra of Co-BDCN-24h, Co$\mathrm{BDCN}-3 \mathrm{~h}$, terephthalamide, and terephthalonitrile (dissolved in DMSO-d6 liquids) and DMSO-d6 in liquid state. c Solid-state ${ }^{13} \mathrm{C}$ NMR spectra of Co-BDCN-24h. d TG curves of Co-BDCN-24h 
while the absorption band at $865 \mathrm{~cm}^{-1}$ can be ascribed to the $v(\mathrm{C}-\mathrm{C})$ stretching vibration of $\mathrm{Ar}-\mathrm{C}=\mathrm{O}$. Besides, two characteristic bands of $v\left(\mathrm{NH}_{2}\right)$ stretching vibration are observed at 3366 and $3169 \mathrm{~cm}^{-1}$, whereas the weak absorptions at 1130 and $735-660 \mathrm{~cm}^{-1}$ correspond to the $v\left(\mathrm{NH}_{2}\right)$ rocking vibration. The aforementioned absorption bands can be found in pure terephthalamide. However, for Co-BDCN-24h, new peaks appeared at $1582 \mathrm{~cm}^{-1}$ and can be assigned to the asymmetric stretching vibration of $\mathrm{C}=\mathrm{O}$. The peaks at $3298-3216,1397,1378$, and $1356 \mathrm{~cm}^{-1}$ can be assigned to $v\left(\mathrm{NH}_{2}\right)$ stretching vibration, $v(\mathrm{C}-\mathrm{N})$, amide III and symmetric stretching vibration of $\mathrm{C}=\mathrm{O}$, respectively. The redshift of $v(\mathrm{C}=\mathrm{O})$ and the variations of $v\left(\mathrm{NH}_{2}\right)$ are due to the participation of amide group in coordination. These facts corroborate the hydrolysis of cyano group to amide group in a mass hydrothermal process [44] and subsequent coordination of $\mathrm{Co}^{2+}$ with amide in Co-BDCN24h, as depicted in Scheme 1.

The ${ }^{1} \mathrm{H}$ NMR spectra in liquid state are shown in Fig. 1b. The chemical shift of $\mathrm{H}$ in $-\mathrm{D}_{2} \mathrm{H}$ of DMSO-d6 was set at $2.5 \mathrm{ppm}$ (Fig. S1). A well-defined peak is detected at $8.10 \mathrm{ppm}$ for the $\mathrm{H}$ (-Ar) of terephthalonitrile, while three resonances of intensity ratio of 1:2:1 at $7.52 \mathrm{ppm}\left(\mathrm{H}_{\mathrm{a}}\right.$,$\left.\mathrm{NH}_{2}\right), 7.92 \mathrm{ppm}(\mathrm{H},-\mathrm{Ar})$, and $8.09 \mathrm{ppm}\left(\mathrm{H}_{\mathrm{b}},-\mathrm{NH}_{2}\right)$ are observed in the terephthalamide (the two protons in $-\mathrm{NH}_{2}$ of the amide group show different chemical shifts due to magnetic anisotropy, electric field, and steric effects) [45]. For the formation of amide groups in Co-BDCN-3h, these three broad peaks appear at the same positions. Due to the successful coordination of $\mathrm{Co}^{2+}$ and terephthalamide, CoBDCN-24h could not dissolve in DMSO-d6. As a result, no resonance could be detected in the positions. Solid-state ${ }^{13} \mathrm{C}$ NMR spectra of terephthalonitrile, terephthalamide, and Co-BDCN-24h are plotted. In contrast with the welldefined peaks of terephthalonitrile and terephthalamide (Fig. S2), the peaks of Co-BDCN-24h (Fig. 1c) are very broad (FWHM $\approx 200 \mathrm{ppm}$ ) due to the effect of paramagnetic $\mathrm{Co}^{2+}$ center.

TGA was used to investigate the thermal response of Co-BDCN-24h. As shown in Fig. 1d, before the

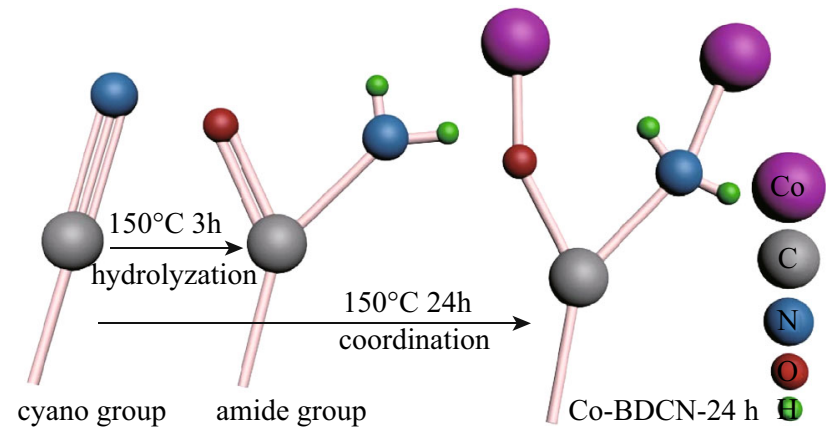

Scheme 1 The forming process of Co-BDCN-24h
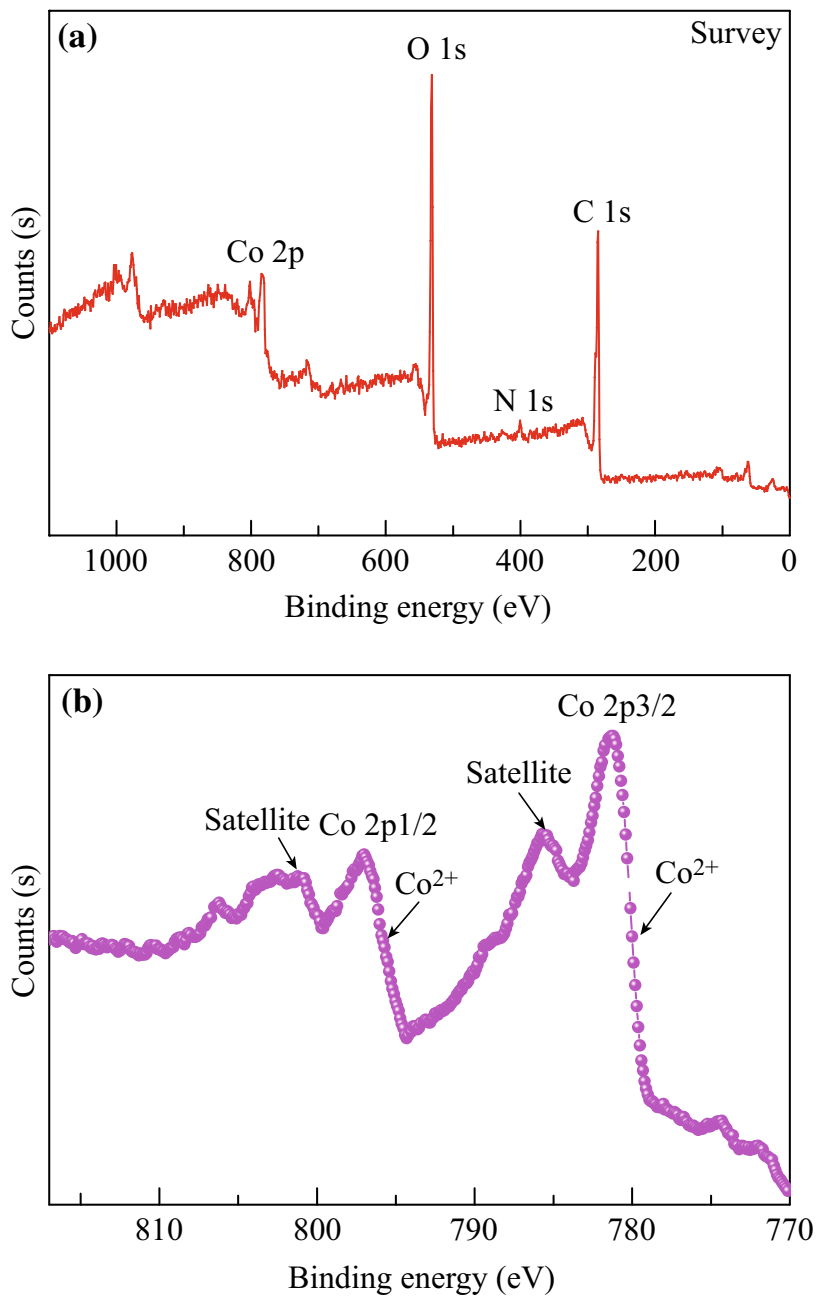

Fig. 2 a XPS surveys and b high-resolution Co 2p XPS spectra of Co-BDCN-24h, from which the existence of $\mathrm{C}, \mathrm{N}, \mathrm{O}$, and $\mathrm{Co}^{2+}$ was determined

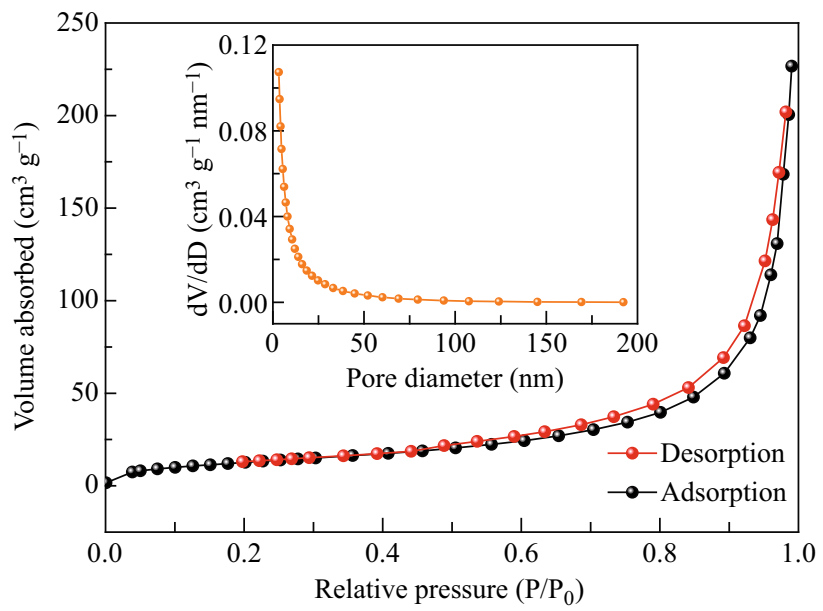

Fig. 3 Nitrogen adsorption/desorption isotherm of Co-BDCN-24h. Inset: the pore-size distribution calculated based on the desorption branch of the corresponding isotherm 

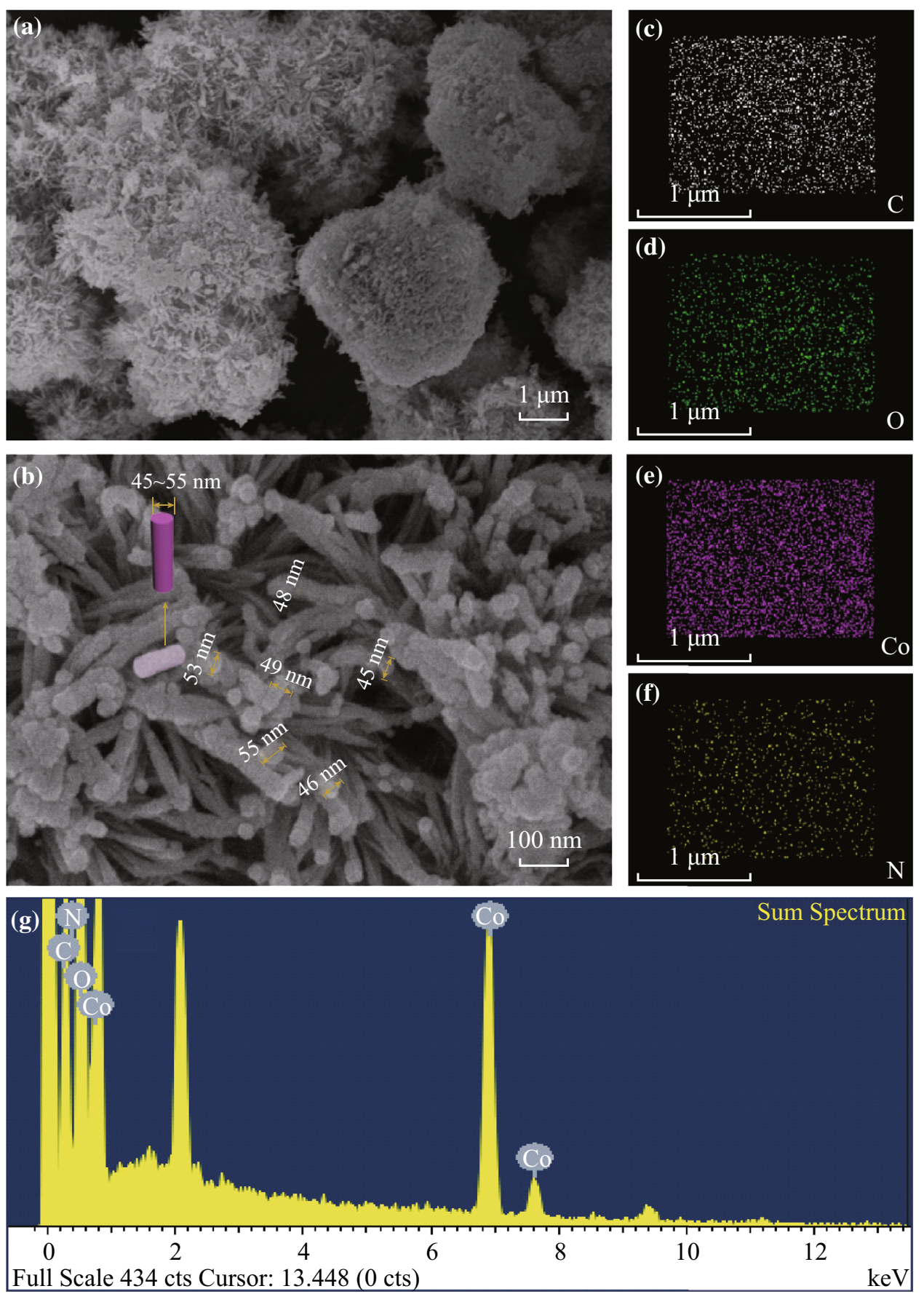

Fig. 4 a, b SEM micrographs of the synthesized Co-BDCN-24h at low and high magnifications. EDS elemental mapping images (c C, d O, e Co, and $\mathbf{f} \mathrm{N}$ ) and $\mathbf{g}$ whole-energy spectra of Co-BDCN-24h. The peak at $\sim 2 \mathrm{keV}$ in the EDS spectrum is attributed to gold

decomposition, continuous weight loss corresponds to the loss of coordinated solvent or the free $\mathrm{H}_{2} \mathrm{O}$ molecules. Subsequently, rapid weight loss in TG curves demonstrates decomposition of the Co-BDCN-24h skeleton above $257^{\circ} \mathrm{C}$. After the decomposition of organic linkers is complete, at $\sim 314{ }^{\circ} \mathrm{C}$, the residual material is converted to $\mathrm{Co}_{3} \mathrm{O}_{4}$. Finally, $46.5 \%$ of $\mathrm{Co}-\mathrm{BDCN}-24 \mathrm{~h}$ was retained, corresponding to $34.2 \%$ Co species. Furthermore, the form of $\mathrm{Co}^{2+}$ was also determined by XPS in Fig. 2 .

Nitrogen adsorption-desorption isotherms were measured at $77 \mathrm{~K}$ to determine the mean pore diameters and surface areas (Fig. 3). A mixed H3- and H1-type hysteresis loop of III isotherm reveals a combination of inter-particle and structural pores. Besides, a wide distribution of pore sizes $(<4-120 \mathrm{~nm})$ is observed for Co-BDCN-24h, 

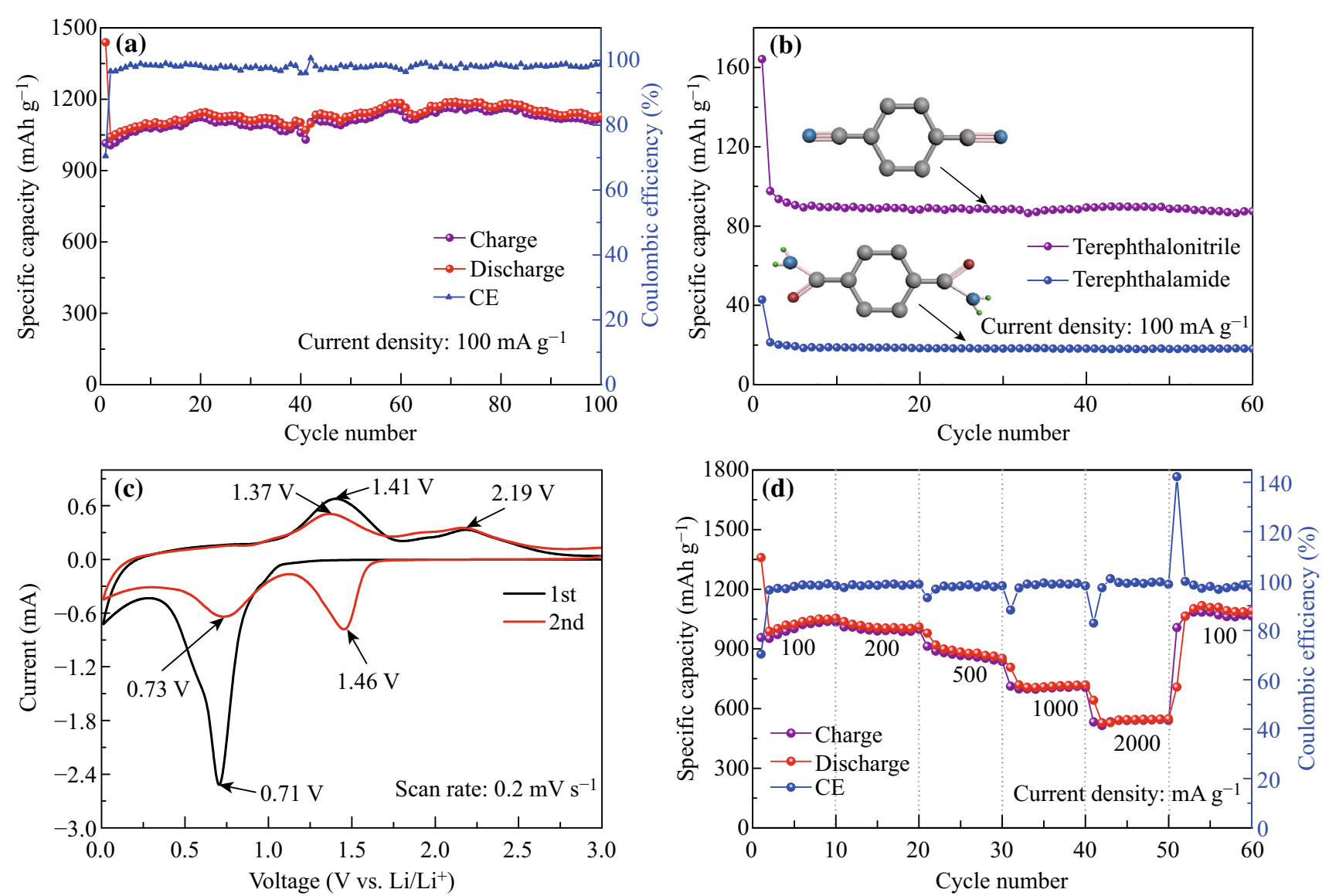

Fig. 5 a Cycling performance and coulombic efficiency of Co-BDCN-24h at $100 \mathrm{~mA} \mathrm{~g}^{-1}$. b Cycling performance and coulombic efficiency of terephthalonitrile and terephthalamide at $100 \mathrm{~mA} \mathrm{~g}^{-1}$. c Cyclic voltammograms for the first two cycles of Co-BDCN-24h at a scan rate of $0.2 \mathrm{mV} \mathrm{s}^{-1}$. d Rate performance of Co-BDCN-24h

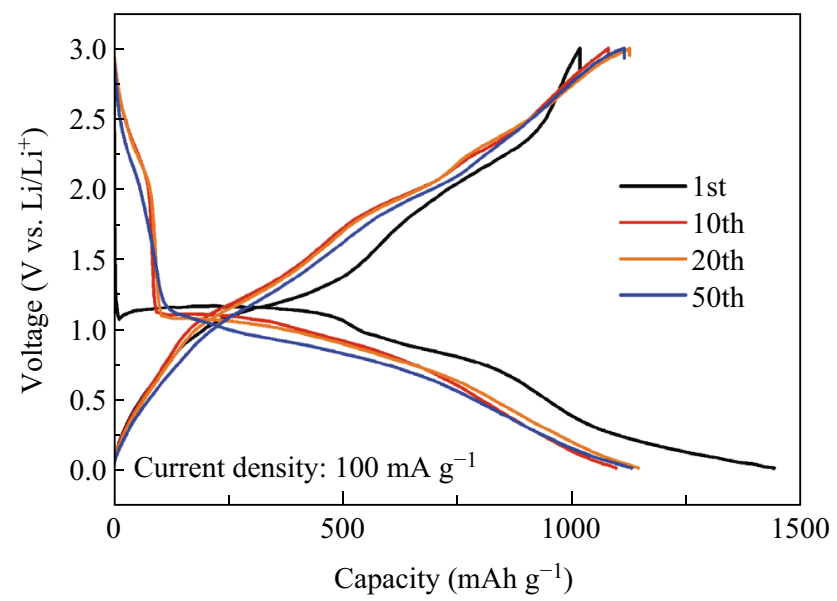

Fig. 6 Galvanostatic charge-discharge profiles of Co-BDCN-24h at $100 \mathrm{~mA} \mathrm{~g}^{-1}$

demonstrating the coexistence of mesopores and macropores. A surface area of $24.5 \mathrm{~m}^{2} \mathrm{~g}^{-1}$, a total pore volume of $0.35 \mathrm{~cm}^{3} \mathrm{~g}^{-1}$, and a mean pore diameter of $28.7 \mathrm{~nm}$ were determined by the Brunauer-Emmett-Teller (BET) method. Unlike traditional MOFs with ultra-high surface

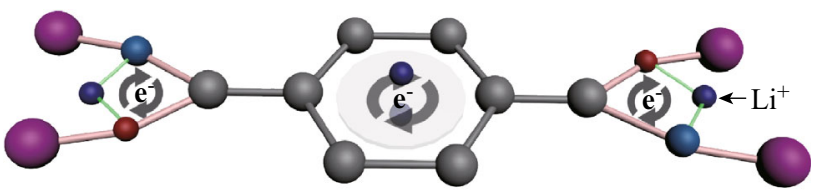

Scheme 2 The schematic view of lithiation sites for $\mathrm{Li}^{+}$adsorbed on benzene ring and amide group with the electron-donating effect of Co-BDCN-24h

area, the moderate specific area of Co-BDCN-24h may weaken accessorial secondary reactions with the electrolyte $[32,42,46]$.

Only three well-defined diffraction peaks of Co-BDCN24 , at $2 \theta=10.1^{\circ}, 11.2^{\circ}$, and $20.0^{\circ}$, were observed in PXRD patterns (Fig. S3), which indicates that most samples are present in the amorphous form. Figure 4a shows a full view of Co-BDCN-24h with uniform morphology, indicating a unified structure even in an amorphous state. Higher-magnification SEM images (Fig. 4b) reveal that Co-BDCN-24h is composed of nanowires with a diameter distribution of 45-55 $\mathrm{nm}$. Elemental analysis using energydispersive X-ray spectroscopy (EDS) shows the 


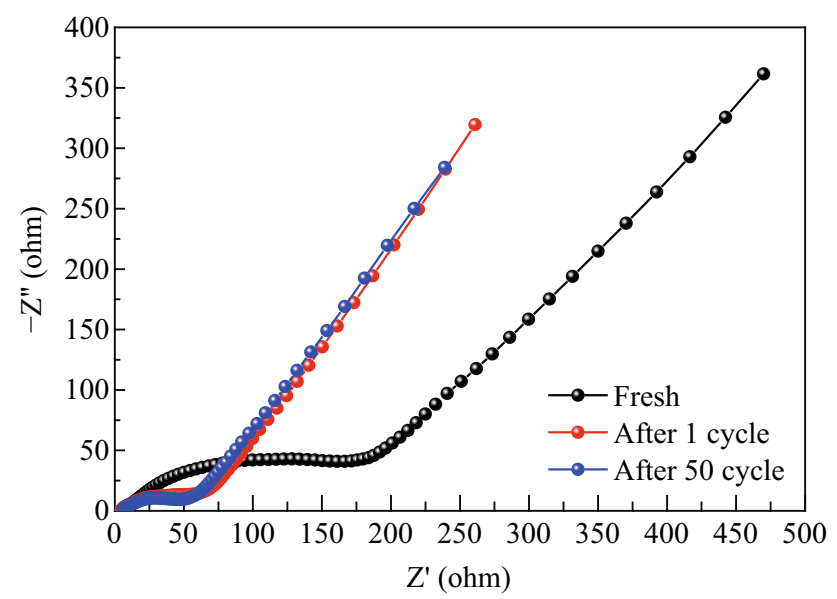

Fig. 7 Nyquist plots of Co-BDCN electrode at different cycling intervals

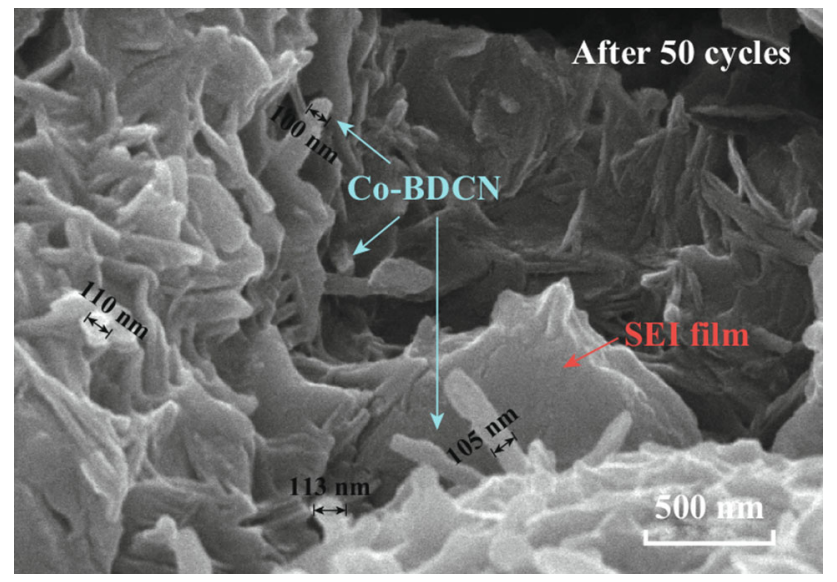

Fig. 8 SEM micrograph of Co-BDCN electrode after 50 cycles

homogeneous distribution of $\mathrm{Co}, \mathrm{O}, \mathrm{C}$, and $\mathrm{N}$ in Co$\mathrm{BDCN}-24 \mathrm{~h}$. On the basis of above-mentioned analysis, CoBDCN-24h can be defined as an amorphous coordination polymer with nanowire morphology.

The cycling performance and coulombic efficiency of Co-BDCN-24h were tested at $100 \mathrm{~mA} \mathrm{~g}^{-1}$ in a voltage range of $0.01-3.0 \mathrm{~V}$ versus $\mathrm{Li} / \mathrm{Li}^{+}$. As shown in Fig. 5a, the initial cycle coulombic efficiency (CE) was calculated to be $70.54 \%$ by the discharge and charge capacities of 1439 and $1015 \mathrm{mAh} \mathrm{g}^{-1}$, respectively. As the side reactions of the electrode disappeared after several cycles, the subsequent charge/discharge curves are analogous (10th, 20th, and 50th, as shown in Fig. 6), indicating a reversible insertion/extraction of $\mathrm{Li}^{+}$. After 100 galvanostatic charge/ discharge cycles, a reversible capacity of $1132 \mathrm{mAh} \mathrm{g}^{-1}$ was obtained. To the best of our knowledge, this should be one of the best LIB performances among MOF- and CPbased anode materials that operate at a rate of $100 \mathrm{~mA} \mathrm{~g}^{-1}$ (Table S1). Moreover, almost $100 \%$ of the coulombic efficiencies are retained in the subsequent cycles, indicating a facile intercalation/extraction of $\mathrm{Li}^{+}$and an efficient transport of ions and electrons in Co-BDCN-24h. In contrast, when operated under the same test conditions, the reversible capacities of terephthalamide and terephthalonitrile are only 18 and $85 \mathrm{mAh} \mathrm{g}^{-1}$, respectively (Fig. 5b). Therefore, we suppose that the ultra-high stability of Co-BDCN-24h should be attributed to synergistic effects of organic linkers and metal centers.

The electrochemical behavior and the reaction mechanism of as-prepared Co-BDCN-24h were also studied by cyclic voltammetry (CV) measurements on 2032 cells in the voltage range of $0.01-3.0 \mathrm{~V}$. Figure $5 \mathrm{c}$ presents the first two consecutive segments in the CV curves. A sharp cathodic peak is observed at $\sim 0.71 \mathrm{~V}$, which can be attributed to the associated electrolyte decomposition and the formation of SEI film on the surface of electrode. Two cathodic peaks at 0.73 and $1.46 \mathrm{~V}$ are observed in the subsequent sweep. The peaks were centered at 1.41-1.37 and $2.19 \mathrm{~V}$ during the anodic scans. The two reduction peaks in CV curves could be mainly attributed to insertion of $\mathrm{Li}^{+}$to different organic moieties (benzene ring and amide group) [39, 42]. The electron-donating effect of the oxygen and nitrogen atoms in the amide groups, and that of the benzene ring, should be the main impetus in storing lithium ion (Scheme 2).

Rate performance was also studied to further explore the electrochemical capability of Co-BDCN-24h. Figure 5d shows the change of cycling performance with increasing rates: $100,200,500,1000$, and $2000 \mathrm{~mA} \mathrm{~g}^{-1}$. The charge capacities corresponding to these rates are $1000 \pm 35$, $1020 \pm 30,866 \pm 13,713 \pm 7$, and $538 \pm 10 \mathrm{mAh} \mathrm{g}^{-1}$, respectively. After repeating the rate test at $100 \mathrm{~mA} \mathrm{~g}^{-1}$ for 50 cycles, the capacity is recovered with a value of about $1100 \mathrm{~mA} \mathrm{~g}^{-1}$ and is sustained at a steady value in the subsequent cycles, which indicates that the Co-BDCN-24h anode remains stable during the rate cycling process.

The Nyquist plots for a fresh sample of Co-BDCN-24h, measured after 1 and 50 cycles, are shown in Fig. 7. The frequency range was set between $0.01 \mathrm{~Hz}$ and $1 \mathrm{MHz}$ with an AC amplitude of $10 \mathrm{mV}$. The solution resistances $\left(R_{\mathrm{s}}\right)$ are $6.7,4.6$, and $5.9 \Omega$, respectively, while the charge transfer resistances $\left(R_{\mathrm{ct}}\right)$ are 147.1, 57.0, and $50.4 \Omega$, respectively. The decrease in $R_{\mathrm{ct}}$ after the first cycle indicates an improved conductivity due to the activation and a better wetting of the electrodes. The small value of $R_{\mathrm{ct}}$ indicates good $\mathrm{Li}^{+}$diffusion into the Co-BDCN-24h electrode. An ex situ SEM image of Co-BDCN-24h electrode at $0.01 \mathrm{~V}$, which was taken after 50 cycles, is displayed in Fig. 8. Nanowire-like structures with a diameter of over $100 \mathrm{~nm}$ are observed, indicating that the initial morphology is preserved. The increase in diameter might be attributed to the $\mathrm{Li}^{+}$intercalation into the Co-BDCN nanowire and the formation of SEI films (over $25 \mathrm{~nm}$ ). 


\section{Conclusion}

In the past, CPs or MOFs based on carboxylate ligands, such as 1,3,5-benzenetricarboxylate and 1,4-benzenedicarboxylate, have shown potential for $\mathrm{Li}^{+}$storage. In this work, an amide-group-based CP, Co-BDCN-24h, was synthesized and characterized for the first time. The CoBDCN-24h electrode, with uniform nanowire morphology, demonstrated ultra-high capacity for $\mathrm{Li}^{+}$storage, i.e., 1132 $\mathrm{mAh} \mathrm{g}^{-1}$ at $100 \mathrm{~mA} \mathrm{~g}^{-1}$ (after 100 cycles). The great reversible capacity and superior cycling stability were attributed to the synergistic effect between metal centers and organic ligands, as well as the preservation of the nanowire morphology during cycling. This work provided an alternative to conjugated dicarboxylate-based $\mathrm{MOF}$ anode materials.

Acknowledgements This work is supported by Basic Research Project of Shanghai Science and Technology Committee (14JC1491000), the Large Instruments Open Foundation of East China Normal University, National Natural Science Foundation of China for Excellent Young Scholars (21522303), National Natural Science Foundation of China (21373086), National Key Basic Research Program of China (2013CB921800) and National High Technology Research and Development Program of China (2014AA123401)

Open Access This article is distributed under the terms of the Creative Commons Attribution 4.0 International License (http://crea tivecommons.org/licenses/by/4.0/), which permits unrestricted use, distribution, and reproduction in any medium, provided you give appropriate credit to the original author(s) and the source, provide a link to the Creative Commons license, and indicate if changes were made.

\section{References}

1. M. Armand, J.M. Tarascon, Building better batteries. Nature 451(7179), 652-657 (2008). https://doi.org/10.1038/451652a

2. A. Banerjee, V. Aravindan, S. Bhatnagar, D. Mhamane, S. Madhavi, S. Ogale, Superior lithium storage properties of $\alpha$ $\mathrm{Fe}_{2} \mathrm{O}_{3}$ nano-assembled spindles. Nano Energy 2(5), 890-896 (2013). https://doi.org/10.1016/j.nanoen.2013.03.006

3. W. Yin, Y. Shen, F. Zou, X. Hu, B. Chi, Y. Huang, Metal-organic framework derived $\mathrm{ZnO} / \mathrm{ZnFe}_{2} \mathrm{O}_{4} / \mathrm{C}$ nanocages as stable cathode material for reversible lithium-oxygen batteries. ACS Appl. Mater. Interfaces 7(8), 4947-4954 (2015). https://doi.org/10. 1021/am509143t

4. F. Zheng, D. Zhu, X. Shi, Q. Chen, Metal-organic frameworkderived porous $\mathrm{Mn}_{1.8} \mathrm{Fe}_{1.2} \mathrm{O}_{4}$ nanocubes with an interconnected channel structure as high-performance anodes for lithium ion batteries. J. Mater. Chem. A 3(6), 2815-2824 (2015). https://doi. org/10.1039/C4TA06150K

5. C. Li, T. Chen, W. Xu, X. Lou, L. Pan, Q. Chen, B. Hu, Mesoporous nanostructured $\mathrm{Co}_{3} \mathrm{O}_{4}$ derived from MOF template: a high-performance anode material for lithium-ion batteries. J. Mater. Chem. A 3(10), 5585-5591 (2015). https://doi.org/10. 1039/C4TA06914E
6. X. Hu, C. Li, X. Lou, X. Yan, Y. Ning, Q. Chen, B. Hu, Controlled synthesis of $\mathrm{Co}_{\mathrm{x}} \mathrm{Mn}_{3-\mathrm{x}} \mathrm{O}_{4}$ nanoparticles with a tunable composition and size for high performance lithium-ion batteries. RSC Adv. 6(59), 54270-54276 (2016). https://doi.org/10.1039/ C6RA08700K

7. X. Hu, C. Li, X. Lou, Q. Yang, B. Hu, Hierarchical CuO octahedra inherited from copper metal-organic frameworks: high-rate and high-capacity lithium-ion storage materials stimulated by pseudocapacitance. J. Mater. Chem. A 5(25), 12828-12837 (2017). https://doi.org/10.1039/C7TA02953E

8. J. Guo, B. Jiang, X. Zhang, H. Liu, Monodisperse $\mathrm{SnO}_{2}$ anchored reduced graphene oxide nanocomposites as negative electrode with high rate capability and long cyclability for lithium-ion batteries. J. Power Sources 262, 15-22 (2014). https://doi.org/10. 1016/j.jpowsour.2014.03.085

9. X. Zhang, H. Chen, Y. Xie, J. Guo, Ultralong life lithium-ion battery anode with superior high-rate capability and excellent cyclic stability from mesoporous $\mathrm{Fe}_{2} \mathrm{O}_{3} @ \mathrm{TiO}_{2}$ core-shell nanorods. J. Mater. Chem. A 2(11), 3912-3918 (2014). https://doi.org/ $10.1039 / \mathrm{c} 3 \mathrm{ta} 14317 \mathrm{a}$

10. J. Guo, H. Zhu, Y. Sun, L. Tang, X. Zhang, Pie-like free-standing paper of graphene paper@ $\mathrm{Fe}_{3} \mathrm{O}_{4}$ nanorod array@carbon as integrated anode for robust lithium storage. Chem. Eng. J. 309, 272-277 (2017). https://doi.org/10.1016/j.cej.2016.10.041

11. C. Guan, X. Wang, Q. Zhang, Z. Fan, H. Zhang, H.J. Fan, Highly stable and reversible lithium storage in $\mathrm{SnO}_{2}$ nanowires surface coated with a uniform hollow shell by atomic layer deposition. Nano Lett. 14(8), 4852-4858 (2014). https://doi.org/10.1021/ nl502192p

12. C. Wu, J. Maier, Y. Yu, Sn-based nanoparticles encapsulated in a porous 3D graphene network: advanced anodes for high-rate and long life Li-ion batteries. Adv. Funct. Mater. 25(23), 3488-3496 (2015). https://doi.org/10.1002/adfm.201500514

13. H. Jia, P. Gao, J. Yang, J. Wang, Y. Nuli, Z. Yang, Novel threedimensional mesoporous silicon for high power lithium-ion battery anode material. Adv. Energy Mater. 1, 1036-1039 (2011). https://doi.org/10.1002/aenm.201100485

14. D. Ma, Z. Cao, A. Hu, Si-based anode materials for Li-ion batteries: a mini review. Nano Micro Lett. 6(4), 347-358 (2014). https://doi.org/10.1007/s40820-014-0008-2

15. X. Yu, J.B. Bates, G.E. Jellison, F.X. Hart, A stable thin-film lithium electrolyte: lithium phosphorus oxynitride. J. Electrochem. Soc. 144(2), 524-532 (1997). https://doi.org/10.1149/1. 1837443

16. L. Wang, X. He, J. Li, W. Sun, J. Gao, J. Guo, C. Jiang, Nanostructured phosphorus composite as high-capacity anode materials for lithium batteries. Angew. Chem. Int. Ed. 51(36), 9034-9037 (2012). https://doi.org/10.1002/anie.201204591

17. L. Sun, M. Li, K. Sun, S. Yu, R. Wang, H. Xie, Electrochemical activity of black phosphorus as an anode material for lithium-ion batteries. J. Phy. Chem. C 116(28), 14772-14779 (2012). https:// doi.org/10.1021/jp302265n

18. Y. Kim, Y. Park, A. Choi, N.S. Choi, J. Kim, J. Lee, J.H. Ryu, S.M. Oh, K.T. Lee, An amorphous red phosphorus/carbon composite as a promising anode material for sodium ion batteries. Adv. Mater. 25(22), 3045-3049 (2013). https://doi.org/10.1002/ adma.201204877

19. P. Poizot, S. Laruelle, S. Grugeon, L. Dupont, J.M. Tarascon, Nano-sized transition-metal oxides as negative-electrode materials for lithium-ion batteries. Nature 407(6803), 496-499 (2000). https://doi.org/10.1038/35035045

20. D. Deng, J.Y. Lee, Reversible storage of lithium in a rambutanlike tin-carbon electrode. Angew. Chem. Int. Ed. 48(9), 1660-1663 (2009). https://doi.org/10.1002/anie.200803420

21. W. Zhang, J. Hu, Y. Guo, S. Zheng, L. Zhong, W. Song, L. Wan, Tin-nanoparticles encapsulated in elastic hollow carbon spheres 
for high-performance anode material in lithium-ion batteries. Adv. Mater. 20(6), 1160-1165 (2008). https://doi.org/10.1002/ adma.200701364

22. S. Yang, X. Feng, S. Ivanovici, K. Müllen, Fabrication of graphene-encapsulated oxide nanoparticles: towards high-performance anode materials for lithium storage. Angew. Chem. Int. Ed. 49(45), 8408-8411 (2010). https://doi.org/10.1002/anie. 201003485

23. H. Li, M. Eddaoudi, M. O'Keeffe, O.M. Yaghi, Design and synthesis of an exceptionally stable and highly porous metalorganic framework. Nature 402(6759), 276-279 (1999). https:// doi.org/10.1038/46248

24. M. Zhao, K. Yuan, Y. Wang, G. Li, J. Guo, L. Gu, W. Hu, H. Zhao, Z. Tang, Metal-organic frameworks as selectivity regulators for hydrogenation reactions. Nature 539(7627), 76-80 (2016). https://doi.org/10.1038/nature19763

25. H. Xia, J. Zhang, Z. Yang, S. Guo, S. Guo, Q. Xu, 2D MOF nanoflake-assembled spherical microstructures for enhanced supercapacitor and electrocatalysis performances. Nano Micro Lett. 9(4), 43 (2017). https://doi.org/10.1007/s40820-017-0144-6

26. P. Falcaro, R. Ricco, C.M. Doherty, K. Liang, A.J. Hill, M.J. Styles, MOF positioning technology and device fabrication. Chem. Soc. Rev. 43(16), 5513-5560 (2014). https://doi.org/10. 1039/C4CS00089G

27. Q. Zhu, X. Qiang, Metal-organic framework composites. Chem. Soc. Rev. 43(16), 5468-5512 (2014). https://doi.org/10.1039/ C3CS60472A

28. A. Fateeva, P. Horcajada, T. Devic, C. Serre, J. Marrot et al., Synthesis, structure, characterization, and redox properties of the porous MIL-68(Fe) solid. Eur. J. Inorg. Chem. 24, 3789-3794 (2010). https://doi.org/10.1002/ejic.201000486

29. J. Shin, M. Kim, J. Cirera, S. Chen, G.J. Halder, T.A. Yersak, F. Paesani, S.M. Cohen, Y.S. Meng, MIL-101(Fe) as a lithium-ion battery electrode material: a relaxation and intercalation mechanism during lithium insertion. J. Mater. Chem. A 3(8), 4738-4744 (2015). https://doi.org/10.1039/C4TA06694D

30. Z. Zhang, H. Yoshikawa, K. Awaga, Monitoring the solid-state electrochemistry of $\mathrm{Cu}(2,7-\mathrm{AQDC}) \quad(\mathrm{AQDC}=$ Anthraquinone Dicarboxylate) in a lithium battery: coexistence of metal and ligand redox activities in a metal-organic framework. J. Am. Chem. Soc. 136(46), 16112-16115 (2014). https://doi.org/10. $1021 / j a 508197 \mathrm{w}$

31. L. Hu, X. Lin, J. Mo, J. Lin, H. Gan, X. Yang, Y. Cai, Lead-based metal-organic framework with stable lithium anodic performance. Inorg. Chem. 56(8), 4289-4295 (2017). https://doi.org/10. 1021/acs.inorgchem.6b02663

32. S. Li, Q. Xu, Metal-organic frameworks as platforms for clean energy. Energy Environ. Sci. 6(6), 1656-1683 (2013). https://doi. org/10.1039/c3ee40507a

33. T. Gong, X. Lou, E. Gao, B. Hu, Pillared-layer metal-organic frameworks for improved lithium-ion storage performance. ACS Appl. Mater. Interfaces 9(26), 21839-21847 (2017). https://doi. org/10.1021/acsami.7b05889

34. D. Ji, H. Zhou, Y. Tong, J. Wang, M. Zhu, T. Chen, A. Yuan, Facile fabrication of MOF-derived octahedral $\mathrm{CuO}$ wrapped 3D graphene network as binder-free anode for high performance lithium-ion batteries. Chem. Eng. J. 313, 1623-1632 (2017). https://doi.org/10.1016/j.cej.2016.11.063

35. D. Ji, H. Zhou, J. Zhang, Y. Dan, H. Yang, A. Yuan, Facile synthesis of a metal-organic framework-derived $\mathrm{Mn}_{2} \mathrm{O}_{3}$ nanowire coated three-dimensional graphene network for high-performance free-standing supercapacitor electrodes. J. Mater. Chem. A 4(21), 8283-8290 (2016). https://doi.org/10.1039/C6TA01377E

36. X. Li, F. Cheng, S. Zhang, J. Chen, Shape-controlled synthesis and lithium-storage study of metal-organic frameworks $\mathrm{Zn}_{4} \mathrm{O}(1,3,5 \text {-benzenetribenzoate) })_{2}$. J. Power Sources 160(1), 542-547 (2006). https://doi.org/10.1016/j.jpowsour.2006.01.015

37. K. Saravanan, M. Nagarathinam, P. Balaya, J.J. Vittal, Lithium storage in a metal organic framework with diamondoid topology - a case study on metal formats. J. Mater. Chem. 20(38), 8329-8335 (2010). https://doi.org/10.1039/c0jm01671c

38. Q. Liu, L. Yu, Y. Wang, Y. Ji, J. Horvat, M. Cheng, X. Jia, G. Wang, Manganese-based layered coordination polymer: synthesis, structural characterization, magnetic property, and electrochemical performance in lithium-ion batteries. Inorg. Chem. 52(6), 2817-2822 (2013). https://doi.org/10.1021/ic301579g

39. S. Maiti, A. Pramanik, U. Manju, S. Mahanty, Reversible lithium storage in manganese 1,3,5-benzenetricarboxylate metal-organic framework with high capacity and rate performance. ACS Appl. Mater. Interfaces 7(30), 16357-16363 (2015). https://doi.org/10. 1021/acsami.5b03414

40. L. Gou, L. Hao, Y.X. Shi, S. Ma, X. Fan, L. Xu, D. Li, K. Wang, One-pot synthesis of a metal-organic framework as an anode for Li-ion batteries with improved capacity and cycling stability. J. Solid State Chem. 210(1), 121-124 (2014). https://doi.org/10. 1016/j.jssc.2013.11.014

41. C. Li, X. Hu, X. Lou, Q. Chen, B. Hu, Bimetallic coordination polymer as a promising anode material for lithium-ion batteries. Chem. Commun. 52(10), 2035-2038 (2016). https://doi.org/10. 1039/C5CC07151H

42. C. Li, X. Lou, M. Shen, X. Hu, Z. Guo, Y. Wang, B. Hu, Q. Chen, High anodic performance of Co 1,3,5-benzenetricarboxylate coordination polymers for Li-ion battery. ACS Appl. Mater. Interfaces 8(24), 15352-15360 (2016). https://doi.org/10.1021/ acsami.6b03648

43. M. Armand, S. Grugeon, H. Vezin, S. Laruelle, P. Ribière, P. Poizot, J.M. Tarascon, Conjugated dicarboxylate anodes for Liion batteries. Nat. Mater. 8(2), 120-125 (2009). https://doi.org/ $10.1038 /$ nmat 2372

44. X. Ma, Y. He, Y. Hu, M. Lu, Copper(II)-catalyzed hydration of nitriles with the aid of acetaldoxime. Tetrahedron Lett. 53(4), 449-452 (2012). https://doi.org/10.1016/j.tetlet.2011.11.075

45. R.J. Abraham, L. Griffiths, M. Perez, $1 \mathrm{H}$ NMR spectra. Part $30: 1 \mathrm{H}$ chemical shifts in amides and the magnetic anisotropy, electric field and steric effects of the amide group. Magn. Reson. Chem. 51(3), 143-155 (2013). https://doi.org/10.1002/mrc.3920

46. W. Xia, A. Mahmood, R. Zou, Q. Xu, Metal-organic frameworks and their derived nanostructures for electrochemical energy storage and conversion. Energy Environ. Sci. 8(7), 1837-1866 (2015). https://doi.org/10.1039/C5EE00762C 